\title{
ARTE-EDUCAÇÃO NO ENSINO DO LUGAR EM FEIRA DE SANTANA: OLHARES E POSSIBILIDADES DA CIDADE EDUCATIVA
}

\author{
$\underline{\text { Daiane Correia de Vasconcelos }}^{1}$; Cléa Cardoso da Rocha ${ }^{2}$ \\ 1. Bolsista PROBIC/UEFS, Graduanda em Bacharelado em Geografia, Universidade Estadual de Feira de \\ Santana, e-mail: dcvasconcelos93@gmail.com \\ 2. Orientadora, Departamento de Educação, Universidade Estadual de Feira de Santana, e-mail: \\ cleabase@yahoo.com.br
}

PALAVRAS-CHAVE: arte-educação; cidade educativa; lugar.

\section{INTRODUÇÃO}

A Arte-educação tem o papel fundamental no desenvolvimento da capacidade intelectual do indivíduo, sobretudo através do olhar observador. A interdisciplinaridade inerente a esta permite que se estabeleçam diálogos com outras áreas do conhecimento e o seu caráter lúdico pode tornar o ensino prazeroso e encantador. Esta metodologia de ensino foi sistematizada pioneiramente no Brasil por Ana Mae Barbosa, através da abordagem triangular que se centra em três princípios: contextualização histórica, fazer artístico e apreciação artística (BASTIANI; GUIMARÃES; JÚNIOR; PAZ, 2011).

No mundo contemporâneo ainda encontram-se escolas desvinculadas da realidade social daqueles que a compõe, visto que estão centradas essencialmente no livro didático. Portanto, para que a escola seja uma extensão da vida dos seus alunos, o processo educativo deve ir além dos espaços formais. Nesse sentido, destaca-se a cidade que, por sua vez, é potencialmente educativa, pois segundo Fernandes (2009, p. 59) "[...] contempla um universo ampliado de práticas educativas que acontecem dentro e fora das instituições escolares e não-escolares" e envolve "[...] equipamentos e instituições sociais, artísticas, culturais e de lazer e espaços públicos disponíveis no espectro da cidade, em seus centros urbanos e periféricos".

Gomes (2008, p. 10), destaca que "a cidade é um álbum de imagens obtidas de variados pontos de vista e só essa multiplicidade pode ser de alguma forma representatitva ou geradora de identidades", nesta perspectiva a cidade constitui-se em um locus privilegiado de educação, tornando-se uma cidade educadora. Uma das premissas da cidade educadora, segundo Simões (2010, p. 30), é que "[...] a escola e a família deixariam de ser os intervenientes exclusivos da educação, interagindo hoje, neste campo, inúmeras organizações e escalas de intervenção", logo, os diálogos entre escola e família assumem um papel para além do seu caráter tradicional. A cidade educadora se caracteriza como "uma proposta educadora de educação formal, não formal e informal” (FIGUEIRAS, 2008, p. 19 apud SIMÕES, 2010, p. 30), assim, pode trazer outros olhares para o processo de ensino-aprendizagem, visto a possibilidade de dialogar com espaços alternativos da própria cidade.

Assim sendo acredita-se que a arte-educação no ensino de geografia, tendo como mediadora a cidade educativa, pode contribuir para a construção de conhecimentos aproximando-os da realidade dos alunos, pois possibilita diálogos entre a escola, os espaços experienciados e a formação cidadã e humana. A arte possui a liberdade de (re)significar sentimentos e valores, bem como para questioná-los. Assim, esta

\footnotetext{
${ }^{1}$ A escolha deste conceito é em razão de Feira de Santana ainda ser apenas uma cidade educativa, isso porque não abrange todas as potencialidades educadoras que envolvem diversos segmentos da sociedade que devem trabalhar em conjunto com vistas à superar as funções tradicionais e regulamentadas da cidade.
} 
metodologia educativa pode contribuir para a construção de conhecimentos geográficos pois possibilita a compreensão das leituras e interpretações do espaço, através das formas de percepção e representações de situações cotidianas dos alunos.

Diante do exposto, pretendeu-se responder através desta pesquisa ainda em andamento, os questionamentos: Como formar cidadãos se a educação escolar ainda é essencialmente centrada no livro didático e afasta os alunos da sua realidade, da sua cidade? De que forma a arte-educação pode contribuir para a aproximação entre as realidades experienciadas pelos alunos com os conteúdos geográficos? Que estratégias podem ser pensadas para que a cidade enquanto espaço não-formal potencialmente educativo contribua na construção de conhecimentos geográficos acerca do lugar Feira de Santana, bem como para a formação cidadã?

$\mathrm{Na}$ tentativa de responder aos questionamentos supracitados foi desenvolvida uma pesquisa de caráter qualitativo e extensionista, no âmbito da escola básica, objetivando mediar a produção vídeo sobre Feira de Santana, no estilo Draw my life ${ }^{2}$, com os sujeitos da pesquisa, considerando suas relações com este lugar, que encontram-se sob edição e análise e, portanto, será socializado posteriormente. Para tanto, foi realizada uma oficina na escola-campo tendo como base metodológica uma adaptação à abordagem triangular da Ana Mae Barbosa, visando a contextualização histórica e a apreciação artística, que se deu por meio da socialização de obras da cartografia alternativa e de narrativas sobre Feira de Santana.

\section{MATERIAL E MÉTODOS}

Para o desenvolvimento desta pesquisa serão empregados métodos que estão em consonância com o projeto "Lugar: Formação Docente e Elaboração de Material Didático Pedagógico Sobre Feira de Santana/BA", que é uma pesquisa qualitativa de caráter também extensionista. Dessa maneira, com finalidade de atender aos objetivos propostos lançou-se mão de: 1. Levantamento bibliográfico sobre as temáticas abordadas pela pesquisa (abordagem triangular, arte-educação, cidade educativa, draw my life, educação geográfica, lugar, entre outros); 2. Discussão teórica com grupo de pesquisa através dos encontros quinzenais no Grupo de Estudos do Projeto Lugar; 3. Elaboração de instrumentos para coleta de dados através de diagnóstico prévios com os sujeitos da pesquisa; 4. Planejamento da oficina para a construção de conhecimentos geográficos/cartográficos sobre Feira de Santana enquanto lugar através da arte-educação; 5. Realização e avaliação da oficina atendendo aos princípios da abordagem triangular; 6. Sistematização e análise dos dados coletados; 5. Elaboração de relatórios e publicação dos resultados.

\section{RESULTADOS E/OU DISCUSSÃO}

1. Planejamento e realização da oficina

A presente oficina foi desenvolvida na escola-campo com 35 alunos do $1^{\circ}$ ano do Ensino Médio. Assim, foi abordado sobre a História de Feira de Santana, na perspectiva de aprender através da arte, sob 3 aspectos: 1 . Narrativas sobre o município; 2. Cartografia alternativa; 3. Draw my life. Estes três viéses constituem pesquisas desenvolvidas dentro do mesmo grupo de pesquisa e têm em comum o ensino de geografia através de uma proposta interdisciplinar tendo como pilar a arte-educação, em

\footnotetext{
${ }^{2}$ Draw mylife é um conceito que surgiu em 2010 em formato de tirinhas que se popularizou em 2013 a partir da publicação de um vlogueiro norte-americano no Youtube. Consiste na produção de vídeo tendo como base uma superfície plana e branca em que são feitos desenhos à mão e a gravação ocorre simultaneamente. A edição do vídeo consiste em acelerar/organizar os frames de modo que ilustre a história apresentada (que pode ser narrada ao longo da gravação ou durante a edição).
} 
função disso considerou-se necessário esta articulação para que os alunos tivessem uma visão mais ampla do que é o ensino da geografia através da arte.

No que se refere à proposta de ensino de geografia aliado a arte-educação através do Draw my life, na oficina foram levantados os conhecimentos prévios acerca das temáticas da pesquisa, posteriormente foi apresentada a história do Draw my life, com exemplos de vídeo com a técnica (modelo estático e modelo dinâmico) e discutidos os elementos que compõem este modo de contar uma história. Para a elaboração do produto final, a turma foi dividida em comissões: $1^{a}$ comissão - decidir a temática que será abordada nos desenhos, envolvendo elementos da cartografia alternativa; $2^{\mathrm{a}}$ comissão - elaboração do roteiro do vídeo; $3^{a}$ comissão - desenho da história que seria contada; $4^{\mathrm{a}}$ comissão - fotografia/filmagem da história; $5^{\mathrm{a}}$ comissão - edição do vídeo produzido com a técnica de modelo dinâmico do Draw my life.

O ensino da geografia por meio da arte-educação possibilitou aos alunos vários olhares sobre um mesmo elemento, devido à sua subjetividade, que carregam as experiências destes sujeitos em suas contribuições durante o decorrer da intervenção. Por se tratar de abordagens atuais, observou-se que a turma contribuiu significativamente para o desenvolvimento da oficina e das atividades realizadas ao longo desta, como será demonstrado a seguir nos resultados obtidos através dos instrumentos de coleta de dados durante a oficina.

\section{Resultados da oficina}

Para a coleta de dados foram realizadas a observação durante a oficina, aplicação de questionário diagnóstico (no início da oficina) e aplicação de questionário avaliativo (após a oficina), com alunos com faixa etária entre 14 e 16 anos do $1^{\circ}$ ano do Ensino Médio. Dentre os 35 alunos investigados, a maioria nasceu em Feira de Santana (28 alunos) e residem na área urbana do município (34 alunos). Notou-se que embora residam em Feira de Santana, alguns não gostam do município e caracterizam-o como um lugar que não possui atrativos como, por exemplo, espaços de lazer.

Os sujeitos afirmaram que a arte é significativa para eles pois é uma forma de expressão, de aprendizagem e diversão, que abrange sentimentos, valores e possibilita conhecer a cultura de um determinado lugar. No entanto, quando questionados acerca do que é arte-educação, apenas 7 alunos afirmaram saber o que significa, dentre estes apenas 4 alunos afirmaram já ter estudado algum conteúdo através desta perspectiva, nas disciplinas Artes, História e Música.

No que se refere ao ensino da geografia através da arte-educação, apesar deles nunca terem tido a experiência antes da oficina, 28 alunos afirmaram que acreditam que é possível aprender conteúdos geográficos através da arte.

Após a oficina, foi aplicado o questionário de avaliação a 23 alunos, estes fizeram uma avaliação positiva da oficina de modo geral, caracterizando-a como excelente (10 alunos), ótima (8 alunos) e boa (5 alunos). Sobre a articulação realizada entre os conhecimentos geográficos/cartográficos e a arte-educação durante a oficina, 19 alunos afirmaram que isto contribuiu para ampliar os seus conhecimentos acerca de Feira de Santana enquanto lugar, pois facilitou a aprendizagem e trouxe conteúdos sobre o município que até então eram desconhecidos por eles.

14 alunos afirmaram que a oficina estimulou o interesse deles pela geografia, pois, a partir dela eles perceberam que a geografia é um conhecimento ilimitado e que a geografia pode ser ensinada de uma forma mais dinâmica. Os demais (7 alunos) afirmaram que não estimulou por que não possuem afinidade com a disciplina. Além disso, 10 alunos afirmaram que a oficina contribuiu para a sua aprendizagem mais do 
que as aulas de geografia que não ocorrem numa perspectiva interdisciplinar, pois, facilitou a aprendizagem e deixou-a mais interessante.

Os alunos também fizeram uma avaliação positiva acerca do tema da oficina: excelente (10 alunos), ótimo (5 alunos) e bom ( 7 alunos); bem como do material produzido na oficina: excelente (13 alunos), ótimo (6 alunos) e bom (3 alunos). Ao serem questionados se outros temas geográficos poderiam ser abordados em aulas articulando a geografia com a arte-educação, 13 alunos afirmaram que sim, que gostariam de mais aulas nesta perspectiva interdisciplinar e sugeriram conteúdos da geografia física.

\section{CONSIDERAÇÕES FINAIS}

A arte-educação é um debate atual e que tem se intensificado nos últimos anos, que pode ser visualizado através das constantes evoluções nos documentos oficiais que regem o ensino no país e, paralelamente, traz uma série de questionamentos e opiniões acerca de sua inserção para a construção de conhecimentos. No entanto, apesar da necessidade de inserção de atividades envolvendo arte no âmbito do espaço escolar, nota-se que esta ainda é muito estigmatizada. A escola-campo em questão apesar de desenvolver muitas atividades interdisciplinares, tanto no âmbito do espaço escolar quanto no espaço não escolar, ainda não articulam os conteúdos geográficos com a arte-educação.

Diante dos resultados obtidos através da oficina, acredita-se que esta seja uma das alternativas para tornar o ensino de geografia mais atrativo, menos enfadonho e mnemônico, bem como possibilitar que os alunos conheçam a história de seu município, visto que isso é um ponto de partida para que estes se identifiquem e atribuam significado à este lugar, (re)significando sentimentos e valores, bem como promover o (re)encantamento dos alunos pela geografia.

\section{REFERÊNCIAS}

BASTIANI, Ana Cláudia; GUIMARÃES, Claudio Jorge; JÚNIOR, Anselmo Rodrigues de Andrade; PAZ, Wilton Correia. O papel da educação não-formal e suas contribuições na formação cultural do cidadão. Revista Conexão, v. 7, n. 2, p. 184-193, 2011.

FERNANDES, Renata Sieiro. A cidade educativa como espaço de educação não formal, as crianças e os jovens. Revista Eletrônica de Educação, v. 3, n. 1, p. 58-74, mai. 2009.

GOMES, Paulo César da Costa. Cenários da vida urbana: imagens, espaços e representações. Revista CIDADES, v. 5, n. 7, jan./jun. 2008.

SIMÕES, Jorge Manuel Salgado. Cidades em rede e redes de cidades: o movimento das cidades educadoras. 2010. 118 f. Dissertação (Mestrado em Cidades e Culturas Urbanas), Faculdade de Economia da Universidade de Coimbra, 2010. 